\title{
Humidity Sensors Based on High Performance Graphene/Zirconium Dioxide Nanocomposite Material
}

\author{
Wang-De Lin, ${ }^{1 *}$ Tsan-Chang Chang, ${ }^{2}$ and Ren-Jang $\mathrm{Wu}^{3}$ \\ ${ }^{1}$ Department of Center for General Education, St. Mary's Junior College of Medicine, Nursing and Management, \\ Yilan 26644 Taiwan, ROC \\ ${ }^{2}$ Department of Nursing, Mackay Junior College of Medicine, Nursing, and Management, \\ Taipei 11260 Taiwan, ROC \\ ${ }^{3}$ Department of Applied Chemistry, Providence University, \\ Taichung 43301 Taiwan, ROC
}

(Received January 29, 2018; accepted April 16, 2018)

Keywords: graphene, $\mathrm{ZrO}_{2}$, humidity sensor, sensitivity, nanocomposite

This paper reports a novel graphene $(\mathrm{G}) /$ zirconium dioxide $\left(\mathrm{ZrO}_{2}\right)$ nanocomposite produced using a sol-gel method with various weight percentages of graphene for use in humidity sensors. The morphological and structural properties of the $\left(\mathrm{G} / \mathrm{ZrO}_{2}\right)$ were characterized using X-ray diffraction (XRD), Fourier transform infrared (FTIR), transmission electron microscopy (TEM), and energy-dispersive X-ray spectroscopy (EDX). The response characteristics of the sensor, including sensitivity, hysteresis, response time, and recovery time, were investigated from theoretical as well as experimental perspectives. Experimental results revealed a linear functional relationship between shifts in the impedance of the sensor and variations in relative humidity. The sensor with $40 \mathrm{wt} \% \mathrm{G} / \mathrm{ZrO}_{2}$ nanocomposite demonstrated a sensitivity $(S=$ 4011) exceeding that of the other samples. At all humidity levels, the humidity hysteresis values remained low, and the response and recovery times were very rapid ( 5 and $20 \mathrm{~s}$, respectively). These results demonstrate the considerable potential of using $\mathrm{G} / \mathrm{ZrO}_{2}$ nanocomposites in the further development of humidity sensors.

\section{Introduction}

The monitoring of humidity levels is crucial to the operation of medical equipment as well as numerous food production and industrial systems. ${ }^{(1,2)}$ Several ceramic materials, including $\mathrm{TiO}_{2},{ }^{(3)} \mathrm{ZnO},{ }^{(4)} \mathrm{SnO}_{2},{ }^{(5)} \mathrm{B}_{2} \mathrm{O}_{3},{ }^{(6)}$ and $\mathrm{ZrO}_{2},{ }^{(7)}$ have proven particularly effective, due to their superior mechanical, chemical, and thermal stability. ${ }^{(8)}$ A variety of techniques and devices are used for the measurement of humidity, including impedance, ${ }^{(9)}$ capacitance, ${ }^{(10)}$ optics, ${ }^{(11)}$ resistance, ${ }^{(12)}$ and the quartz crystal microbalance. ${ }^{(13)}$ Regardless of the structure, all such devices must be relatively small, easy to fabricate, and inexpensive, while providing high sensitivity, low humidity hysteresis, and rapid response and recovery times. ${ }^{(14)}$

Depending on temperature, $\mathrm{ZrO}_{2}$ can be found in the three phases: monoclinic, tetragonal,

*Corresponding author: e-mail: newwander@smc.edu.tw http://dx.doi.org/10.18494/SAM.2018.1916 
and cubic. Below $1150{ }^{\circ} \mathrm{C}$, this ceramic material has a monoclinic structure with high degree of thermal and chemical stability and excellent toughness. ${ }^{(15)}$ This has led numerous researchers to investigate the application of $\mathrm{ZrO}_{2}$ materials in humidity sensors. ${ }^{(7,16-18)}$ Unfortunately, the sensing performance of $\mathrm{ZrO}_{2}$ is inhibited by pronounced hysteresis. ${ }^{(7)}$ Graphene has a large specific surface area, a large number of reactive sites, high electrical mobility, and excellent thermal conductivity, leading to its widespread use in humidity sensing applications. ${ }^{(19)}$ Recent studies have favoured the use of methylene blue (MB) and rhodamine B dyes (RB) were degraded from water using $\mathrm{ZrO}_{2}$ and zirconium oxide/graphene composites $\left(\mathrm{ZrO}_{2} / \mathrm{GR}\right)$ as photocatalyst. ${ }^{(20)}$ However, no previous study has reported on the use of $\mathrm{G} / \mathrm{ZrO}_{2}$ nanocomposite material for use in humidity sensors.

Is this study, we developed a novel humidity sensor based on a $\mathrm{G} / \mathrm{ZrO}_{2}$ nanocomposite. The humidity-sensing properties of the sensor were measured over a wide range of relative humidity (RH) values (12-90\%) at room temperature. Results from repeated experiments confirm that the proposed sensor has excellent linearity, sensitivity $(S=4011)$, negligible hysteresis $(<2.0 \%)$, quick response time $(5 \mathrm{~s})$, and rapid recovery time (20 s).

\section{Materials and Methods}

\subsection{Materials}

Zirconium oxychloride $\left(\mathrm{ZrClO}_{2} \cdot 8 \mathrm{H}_{2} \mathrm{O}\right)$, anhydrous alcohol $\left(\mathrm{C}_{2} \mathrm{H}_{5} \mathrm{OH}\right)$, and polyvinyl alcohol (PVA) were purchased from Sigma-Aldrich Co., Inc. (USA). High-purity graphene (G) films (>99\%) were supplied by Sigma-Aldrich Co., Inc. (USA). Water was distilled and deionized (DI) using a Milli-Q water purification system (Millipore Corp. France).

\subsection{Fabrication of $\mathrm{G} / \mathrm{ZrO}_{2}$ nanocomposites}

$\mathrm{G} / \mathrm{ZrO}_{2}$ nanocomposite materials were produced by mixing a specific weighed ratio of graphene and $\mathrm{ZrO}_{2}$. We began by mixing $3.22 \mathrm{~g}$ zirconium oxychloride $\left(\mathrm{ZrClO}_{2} \cdot 8 \mathrm{H}_{2} \mathrm{O}\right)$ with 50 $\mathrm{ml}$ anhydrous alcohol under magnetic stirring for $30 \mathrm{~min}$ while heating the solution to $30{ }^{\circ} \mathrm{C} .{ }^{(3)}$ The second step entailed the preparation of graphene powder at specific concentrations. The graphene samples were added to the $\mathrm{ZrO}_{2}$ solution and held at $30^{\circ} \mathrm{C}$ for $3 \mathrm{~d}$ until a powder had formed. The samples were then calcined in air at $600{ }^{\circ} \mathrm{C}$ for $2 \mathrm{~h}$. Various ratios of the sensing material $(5,10,20,30,40$, and $50 \mathrm{wt} \%)$ were tested.

\subsection{Characterization of $\mathrm{G} / \mathrm{ZrO}_{2}$ nanocomposites}

The crystal structure of the $\mathrm{G} / \mathrm{ZrO}_{2}$ nanocomposites was characterized using a XRD6000 Shimadzu X-ray diffractometer with $\mathrm{Cu} \mathrm{K \alpha}$ radiation $(\lambda=0.15405 \mathrm{~nm})$ and a $2 \theta$ range of $10-80^{\circ}$. We also employed a Fourier transform infrared spectrometer (FT-IR D8 Series, Canada) equipped with a mercury-cadmium-telluride (MCT) detector. Spectra of $\mathrm{NaCl}$ crystals with dimensions of $25 \times 4 \mathrm{~mm}^{2}$ (Spectral Systems Inc., \#955-3616; USA) were collected 
in transmission mode at room temperature under atmospheric pressure using a mean of 64 scans from 400 to $5000 \mathrm{~cm}^{-1}$ at a resolution of $2 \mathrm{~cm}^{-1}$. The morphology and structure of the $\mathrm{G} / \mathrm{ZrO}_{2}$ nanocomposites were investigated using transmission electron microscopy and energy dispersive X-ray spectroscopy (TEM/EDX, JEOL JEM-2010), during which the samples were supported on carbon-coated copper grids.

\subsection{Fabrication of humidity sensor}

Sensor chips were fabricated by dip coating the alumina substrate $\left(10 \times 5 \mathrm{~mm}^{2}\right)$ to form a pair of comb-like gold electrodes, followed by the application of PVA as a binder using spin coating at a rotation speed of $1000 \mathrm{rpm}$. The resulting sensing chips were then heated to $70{ }^{\circ} \mathrm{C}$ and held at that temperature for $1 \mathrm{~h}$ before undergoing calcination at $600{ }^{\circ} \mathrm{C}$ for $2 \mathrm{~h}$.

\subsection{Sensing system}

Figure 1 presents a schematic diagram showing the humidity response measurements obtained from the proposed device using a dynamic flow system with sensors housed within a glass chamber. Dynamic testing was conducted by cycling the relative humidity between $12 \%$ and $90 \%$ by adjusting the air/water ratio. In this experiment, the $\mathrm{RH}$ was measured using a hygrometer (Rotronic) with an accuracy of $\pm 0.1 \% \mathrm{RH}$. The impedance response of the sensing film with respect to the humidity was measured by using a chemical impedance analyzer (Delta United, DU 6010) with an applied AC voltage of $1 \mathrm{~V}$ and frequency of $1 \mathrm{kHz}$.

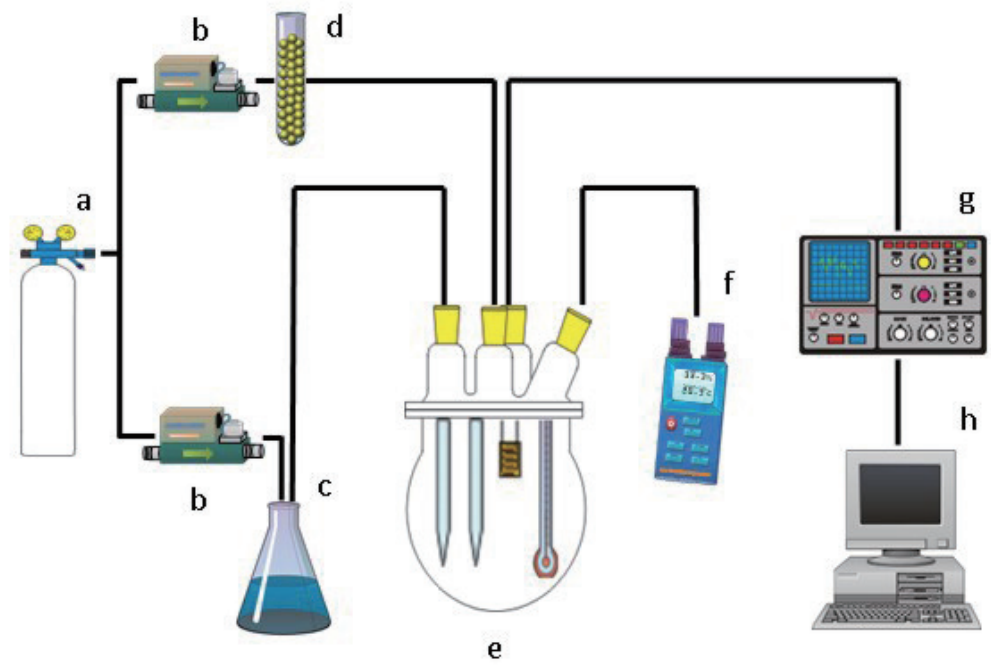

Fig. 1. (Color online) Schematic diagram of experimental setup: (a) air, (b) gas flow controller, (c) water, (d) molecular sieve and desiccating agent, (e) detecting chamber and thermostat, (f) humidity hygrometer, (g) L.C.R.Z. meter, and (h) PC. 


\section{Results and Discussion}

\subsection{Structure characterization}

Figure 2 shows the XRD spectra of graphene, $\mathrm{ZrO}_{2}$, and $\mathrm{G} / \mathrm{ZrO}$ (at 5, 10, 20, 30, 40, and 50 $\mathrm{wt} \%$ ). As shown in spectrum 2(a), the graphene yielded a (002) diffraction peak at $26.42^{\circ} .^{(19)}$ spectrum 2(b) shows peaks at $28.06,30.08,35.08,50.06$, and $60.19^{\circ}(2-\theta$ degree), which can be attributed to the monoclinic phase (JCPDS-07-0343) of the $\mathrm{ZrO}_{2}$ structure. ${ }^{(21)}$ spectrum 2(ch) are the spectra of the various $\mathrm{G} / \mathrm{ZrO}_{2}$ samples, revealing no other crystalline phases. These results indicate that the sensing material was a simple mixture.

Figure 3 shows the FTIR spectra of graphene, $\mathrm{ZrO}_{2}$, and various $\mathrm{G} / \mathrm{ZrO}_{2}$ nanocomposite samples. As shown in spectrum 3(a), graphene has a band at $2323 \mathrm{~cm}^{-1}$ associated with the $\mathrm{C}=\mathrm{O}$ stretching mode, ${ }^{(22)}$ which may be due to the environmental adsorption of $\mathrm{CO}_{2}$ on the surface of the graphene. The FTIR spectrum of $\mathrm{ZrO}_{2}, 3(\mathrm{~b})$, has bands at 501 and $688 \mathrm{~cm}^{-1}$, corresponding to the stretching vibrations of $\mathrm{Zr}-\mathrm{O}$. The broad, weak bands at 3357 and 1589 $\mathrm{cm}^{-1}$ can be attributed to the stretching vibration of hydroxyl groups and interlayer water molecules. ${ }^{(23)}$ The FTIR spectra of the $\mathrm{G} / \mathrm{ZrO}_{2}$ nanocomposite samples are similar to 3(c)-(h), with the main bands corresponding to graphene and $\mathrm{ZrO}_{2}$. These results demonstrate that the $\mathrm{ZrO}_{2}$ effectively covered the surface of the graphene.

The morphology of $\mathrm{ZrO}_{2}$, graphene, and $40 \mathrm{wt} \% \mathrm{G} / \mathrm{ZrO}_{2}$ nanocomposite were characterized by TEM, as shown in Fig. 4. Figure 4(a) shows that the morphology of $\mathrm{ZrO}_{2}$ is primarily spheres with a diameter of approximately $30-40 \mathrm{~nm}$. Figure 4(b) shows smooth graphene sheets stacked irregularly on the surface of the nanocomposite. Figure 4(c) is a TEM image

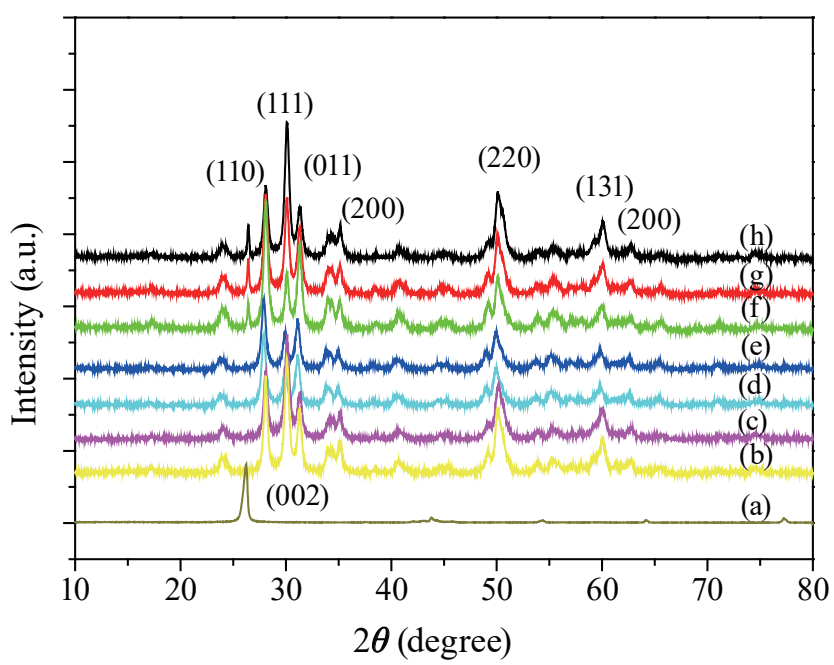

Fig. 2. (Color online) XRD patterns of (a) $\mathrm{G}$, (b) $\mathrm{ZrO}_{2}$, (c) $5 \mathrm{wt} \% \mathrm{G} / \mathrm{ZrO}_{2}$, (d) $10 \mathrm{wt} \% \mathrm{G} / \mathrm{ZrO}_{2}$, (e) 20 wt $\% \mathrm{G} / \mathrm{ZrO}_{2}$, (f) $30 \mathrm{wt} \% \mathrm{G} / \mathrm{ZrO}_{2}$, (g) $40 \mathrm{wt} \% \mathrm{G} / \mathrm{ZrO}_{2}$, and (h) $50 \mathrm{wt} \% \mathrm{G} / \mathrm{ZrO}_{2}$.

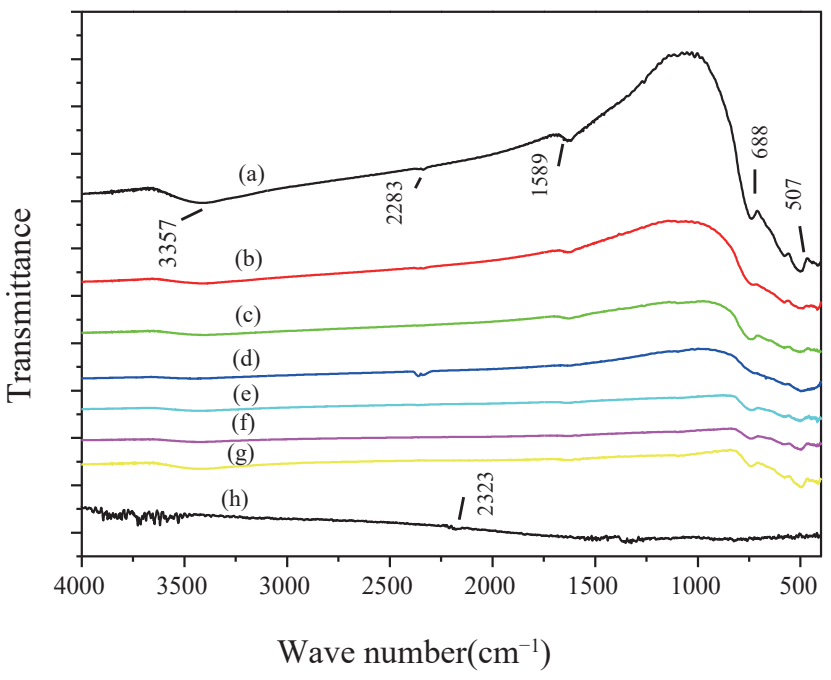

Fig. 3. (Color online) FT-IR spectra of (a) $\mathrm{ZrO}_{2}$, (b) $5 \mathrm{wt} \% \mathrm{G} / \mathrm{ZrO}_{2}$, (c) $10 \mathrm{wt} \% \mathrm{G} / \mathrm{ZrO}_{2}$, (d) $20 \mathrm{wt} \%$ $\mathrm{G} / \mathrm{ZrO}_{2}$, (e) $30 \mathrm{wt} \% \mathrm{G} / \mathrm{ZrO}_{2}$, (f) $40 \mathrm{wt} \% \mathrm{G} / \mathrm{ZrO}_{2}$, (g) $50 \mathrm{wt} \% \mathrm{G} / \mathrm{ZrO}_{2}$, and (h) $\mathrm{G}$. 

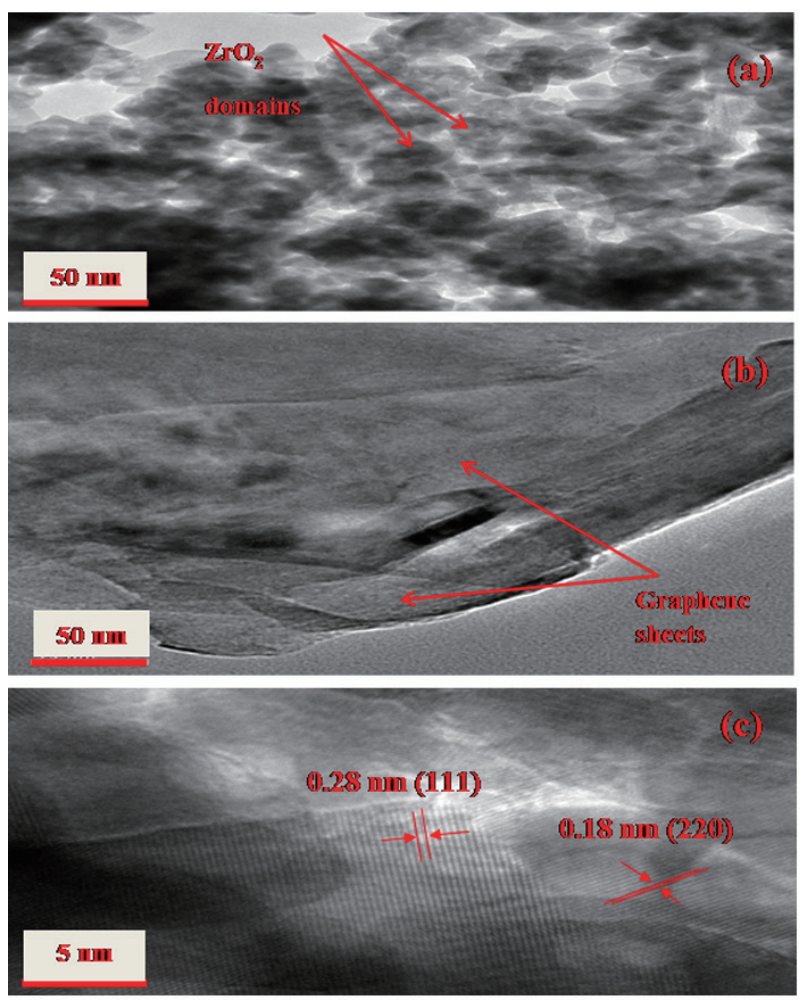

Fig. 4. (Color online) TEM images of (a) $\mathrm{ZrO}_{2}$, (b) graphene, and (c) $40 \mathrm{wt} \% \mathrm{G} /$

revealing lattice fringes on the $40 \mathrm{wt} \% \mathrm{G} / \mathrm{ZrO}_{2}$ nanocomposite. The $d$-spacing of fringe spacing $(d)$ at 0.18 and $0.28 \mathrm{~nm}$ can be attributed to the (220) plane of tetragonal and (111) plane of monoclinic $\mathrm{ZrO}_{2}$, respectively. ${ }^{(24)}$ As shown in Fig. 5, the EDX spectrum of the $40 \mathrm{wt} \%$ $\mathrm{G} / \mathrm{ZrO}_{2}$ nanocomposites reveals peaks of $\mathrm{Zr}, \mathrm{C}$, and $\mathrm{O}$. This provides further proof that the sensing material is a simple mixture.

\subsection{Humidity sensing properties}

Figure 6 illustrates the dependence of impedance on $\mathrm{RH}$ for different content of $\mathrm{G} / \mathrm{ZrO}_{2}$ nanocomposite. At low $\mathrm{RH}$, the impedance decreased gradually with an increase in $\mathrm{RH}$; however, at high $\mathrm{RH}$, the impedance decreased dramatically. Over an $\mathrm{RH}$ range of $12 \%$ to $90 \%$, pure $\mathrm{ZrO}_{2}$ and hydrophobic property of graphene exhibited poor response characteristics, particularly at low humidity levels. In contrast, we observed a steep drop off in the impedance of the hybrid samples over the entire $\mathrm{RH} \%$ range, thereby demonstrating the contribution of graphene to enhancing humidity sensing performance. Increasing the proportion of graphene from 5 to $50 \mathrm{wt} \%$ in $\mathrm{G} / \mathrm{ZrO}_{2}$ led to a corresponding increase in sensitivity. This could be attributed to blockage of the transmission of charge carriers across the surface of the $\mathrm{ZrO}_{2}$. Increasing $\mathrm{RH}$ from $12 \%$ to $90 \%$ decreased the impedance of the $40 \mathrm{wt} \% \mathrm{G} / \mathrm{ZrO}{ }_{2}$ nanocomposite from 14200 to $3.54 \mathrm{k} \Omega$; i.e., variations of approximately four orders of 


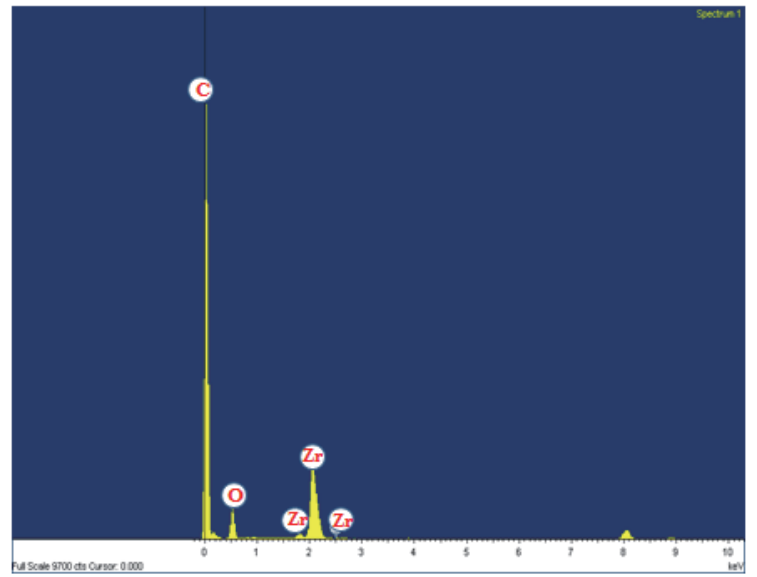

Fig. 5. (Color online) EDX spectrum of the $40 \mathrm{wt} \%$ $\mathrm{G} / \mathrm{ZrO}_{2}$ nanocomposites.

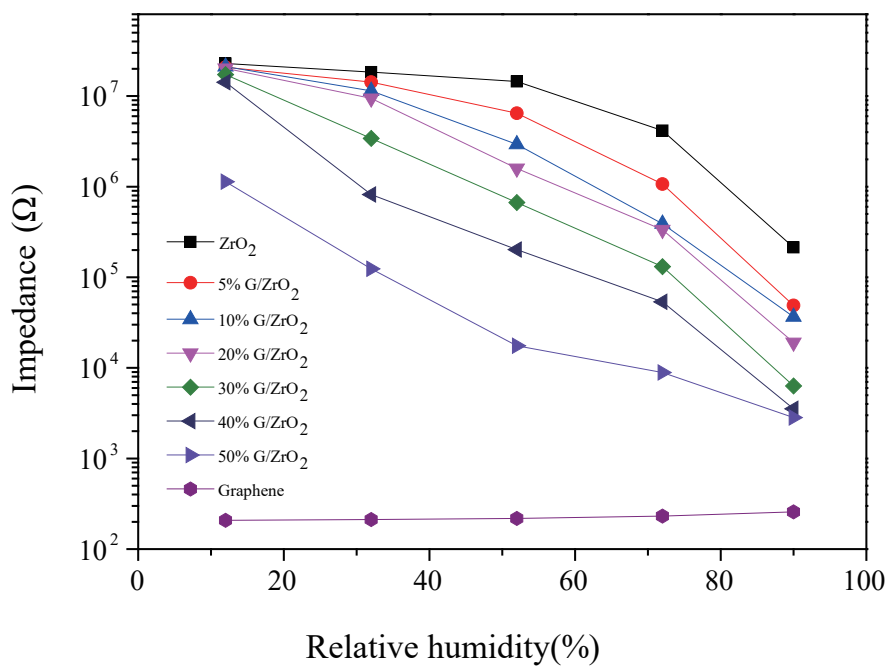

Fig. 6. (Color online) The dependence of impedance on $\mathrm{RH}$ for different content of $\mathrm{G} / \mathrm{ZrO}_{2}$ nanocomposite.

magnitude. The RH sensitivity $(S)$ of the humidity sensor can be defined as $S=R_{d} / R_{h}$, where $R_{d}$ is the resistance of the sensor under dry conditions $(12 \% \mathrm{RH})$, and $R_{h}$ is the resistance at a specific humidity level. ${ }^{(25)}$ Figure 7 and Table 1 present the $S$ values when RH was varied between $12 \%$ and $90 \%$, as follows: $5 \mathrm{wt} \%$ (425.9), $10 \mathrm{wt} \%$ (578.5), 20\% (1058), $30 \mathrm{wt} \%$ (2730), 40wt \% (4011), and 50wt\% (400.7). The $40 \mathrm{wt} \% \mathrm{G} / \mathrm{ZrO}_{2}$ nanocomposite exhibited the highest responsiveness to humidity ( $S=4011$ ); therefore, we selected this nanocomposite for further analysis of RH sensing characteristics.

Humidity hysteresis was investigated by increasing the humidity from 12 to $90 \%$ to promote the adsorption of water molecules and then decreasing it to $12 \%$ to promote desorption. Humidity hysteresis error $(H)$ was calculated using the following expression: $H=\Delta f_{\max } / f_{f s} \times$ $100 \%$, where $\Delta f_{\max }$ is the maximum hysteresis error and $f_{f s}$ is the full-scale response output. Table 2 presents the hysteresis values from $\mathrm{RH}$ of 12 to $72 \%$. The adsorption and desorption curves obtained from this sensor nearly coincide. We determined that the humidity hysteresis error of the $40 \mathrm{wt} \% \mathrm{G} / \mathrm{ZrO}_{2}$ nanocomposite was less than $1.95 \%$, which represents performance on par with the best humidity sensors reported in the literature. ${ }^{(18,26)}$

Response and recovery times are important characteristics in estimating the performance of a humidity sensor. These values are defined as the time required for the total impedance of a sensor to change by $90 \%{ }^{(27)}$ As shown in Fig. 8, the sensor response time of the 40 wt $\% \mathrm{G} / \mathrm{ZrO}_{2}$ device (humidification from 12 to $90 \% \mathrm{RH}$ ) was only $5 \mathrm{~s}$, and the recovery time (desiccation from 90 to $12 \% \mathrm{RH}$ ) was approximately $20 \mathrm{~s}$. This clearly demonstrates the potential of using $40 \mathrm{wt} \% \mathrm{G} / \mathrm{ZrO}_{2}$ in the detection of relative humidity. The humidity sensing properties of the present humidity sensor were compared with those of sensors in the literature ${ }^{(19,28-32)}$ in Table 3. It can be found that our sensor exhibits outstanding sensing properties with high sensitivity, rapid response/recovery times, and small hysteresis in the 


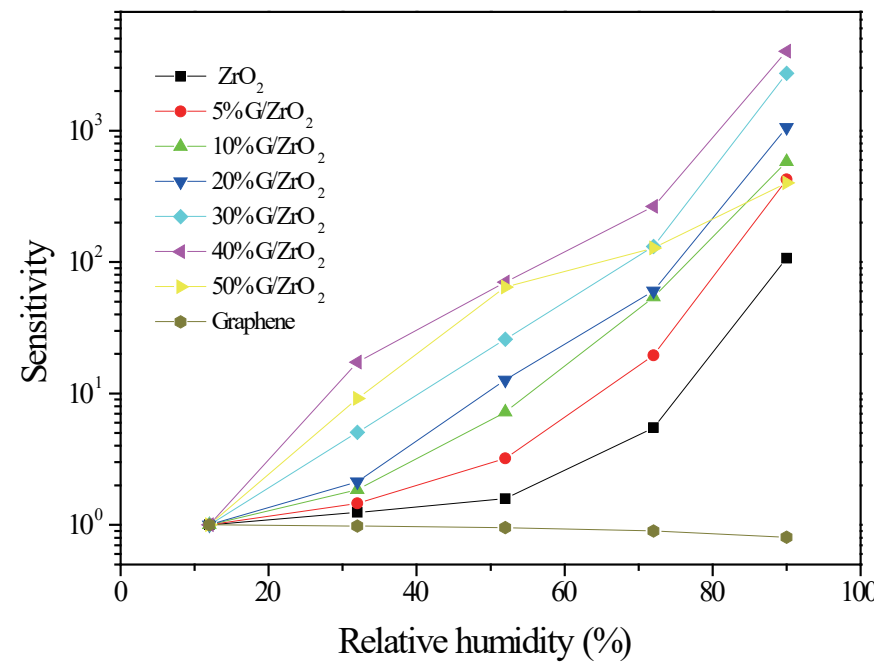

Fig. 7. (Color online) Variation of sensitivity with humidity for different content of $\mathrm{G} / \mathrm{ZrO}_{2}$ nanocomposite.

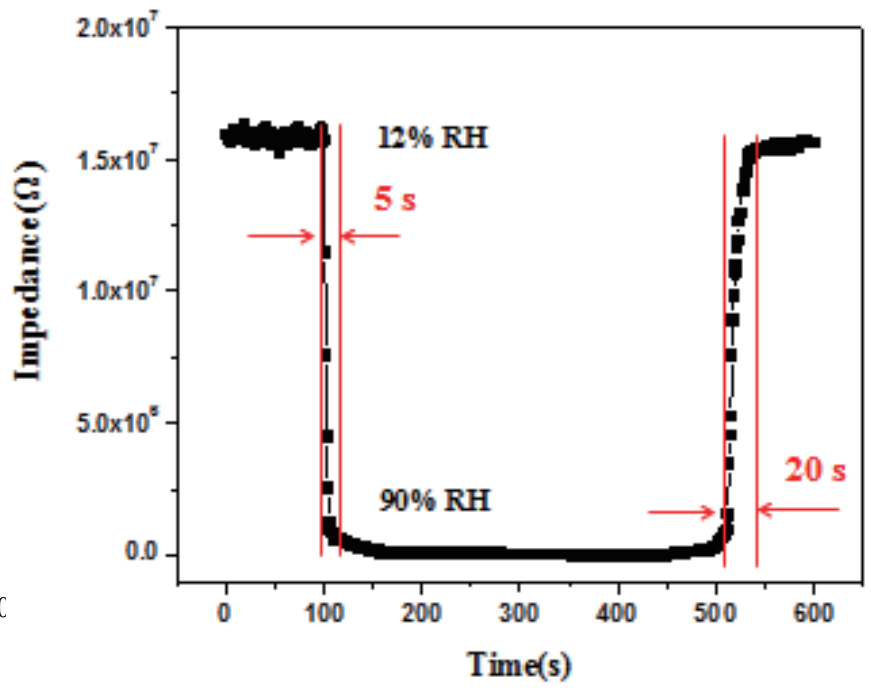

Fig. 8. (Color online) Response and recovery characteristics of $40 \mathrm{wt} \% \mathrm{G} / \mathrm{ZrO}_{2}$ nanocomposite.

Table 1

Calculated sensitivity values for different content of $\mathrm{G} / \mathrm{ZrO}_{2}$ nanocomposite.

\begin{tabular}{lcccccccc}
\hline Sample & $\mathrm{ZrO}_{2}$ & $5 \% \mathrm{ZrO}_{2}$ & $10 \% \mathrm{ZrO}_{2}$ & $20 \% \mathrm{ZrO}_{2}$ & $30 \% \mathrm{ZrO}_{2}$ & $40 \% \mathrm{ZrO}_{2}$ & $50 \% \mathrm{ZrO}_{2}$ & Graphene \\
\hline $12 \%$ & 1 & 1 & 1 & 1 & 1 & 1 & 1 & 1 \\
$32 \%$ & 1.25 & 1.46 & 1.85 & 2.14 & 5.06 & 17.3 & 9.15 & 0.98 \\
$52 \%$ & 1.58 & 3.21 & 7.20 & 12.7 & 25.8 & 70.3 & 64.6 & 0.95 \\
$72 \%$ & 5.50 & 19.5 & 54.3 & 60.3 & 131.6 & 265.3 & 127.8 & 0.90 \\
$90 \%$ & 107.1 & 425.9 & 578.5 & 1058 & 2730 & 4011 & 400.7 & 0.80 \\
\hline
\end{tabular}

Table 2

Calculated hysteresis values for $40 \% \mathrm{G} / \mathrm{ZrO}_{2}$ nanocomposite.

\begin{tabular}{lcccc}
\hline $\mathrm{RH}$ & $12 \%$ & $32 \%$ & $52 \%$ & $72 \%$ \\
\hline Hysteresis & $0.03 \%$ & $1.95 \%$ & $0.95 \%$ & $0.78 \%$ \\
\hline
\end{tabular}

Table 3

Humidity sensor performance of this work compared with the literatures.

\begin{tabular}{|c|c|c|c|c|}
\hline Sensing material & Fabrication method & Measurement range & $\begin{array}{c}\text { Response/ } \\
\text { recovery time (s) }\end{array}$ & References \\
\hline Graphene/ $\mathrm{TiO}_{2}$ & Sol-gel method & $12-90 \%$ RH & $128 / 68$ & [19] \\
\hline $\mathrm{RGO} / \mathrm{SnO}_{2}$ & Hydrothermal synthesis & $11-97 \%$ RH & $102 / 100$ & [28] \\
\hline $\mathrm{GO} / \mathrm{ZnO}$ & Sol-gel immersion & $11.3-97.3 \%$ RH & $9 / 5$ & [29] \\
\hline $\mathrm{GO} / \mathrm{SnO}_{2} / \mathrm{PANI}$ & In-situ oxidative polymerization & 0-97\% RH & $7 / 2$ & [30] \\
\hline Graphene/ZnO & Sol-gel method & $12-90 \% \mathrm{RH}$ & $5 / 90$ & [31] \\
\hline $\mathrm{RGO} / \mathrm{MoS}_{2}$ & Hydrothermal & $10-90 \%$ RH & $30 / 253$ & [32] \\
\hline Graphene $/ \mathrm{ZrO}_{2}$ & Sol-gel method & $12-90 \% \mathrm{RH}$ & $5 / 20$ & This paper \\
\hline
\end{tabular}


detection of humidity.

To evaluate the stability of the $\mathrm{G} / \mathrm{ZrO}_{2}$ nanocomposite fabricated sensor at two different temperatures of 25 and $35^{\circ} \mathrm{C}$, we have exposed the sample in the air for $144 \mathrm{~h}$ followed by a measurement of the impedance to various RH levels. Figure 9 shows in the curves, the product exhibited excellent stability, and there was no significant change in the impedance during this period. We can see from the picture that as the temperature increases, the impedance of the sensor decreases, the reason would be that increasing temperature induces more $\mathrm{H}_{3} \mathrm{O}^{+}$and $\mathrm{H}_{2} \mathrm{O}$ to hydrate into $\mathrm{H}^{+}$. The increasing concentration of $\mathrm{H}^{+}$improves the conductivity of the sensing materials. The conduction increases, and then the impedance of the sensor decreases. ${ }^{(26)}$

\subsection{Humidity sensing mechanism}

The $\mathrm{G} / \mathrm{ZrO}_{2}$ nanocomposites exhibited humidity-sensing properties superior to those of pure graphene and $\mathrm{ZrO}_{2}$. This may be due to the structural and morphological characteristics as well as the hydrophilic functional groups (e.g., hydroxyl groups) attached on the surface. The accumulation of $\mathrm{ZrO}_{2}$ nanoparticles increases the likelihood that water molecules could be obstructed from the inner sensing material. This may explain the hysteresis under high humidity shown in Fig. 10(a). In contrast, the $\mathrm{G} / \mathrm{ZrO}_{2}$ nanocomposites provide numerous channels by which water molecules could penetrate the surface and thereby come into contact with the inner sensing materials, as shown in Fig. 10(b). Under low humidity, the probability of contact between water molecules and $\mathrm{G} / \mathrm{ZrO}_{2}$ nanocomposite material is low. This means that only the outer particles came into contact with water molecules. The fact that the water molecules do not form a continuous layer makes it difficult for the transfer of $\mathrm{H}_{2} \mathrm{O}$ or $\mathrm{H}_{3} \mathrm{O}^{+}$ across the discontinuous water layer. This explains why the $\mathrm{G} / \mathrm{ZrO}_{2}$ nanocomposite exhibit

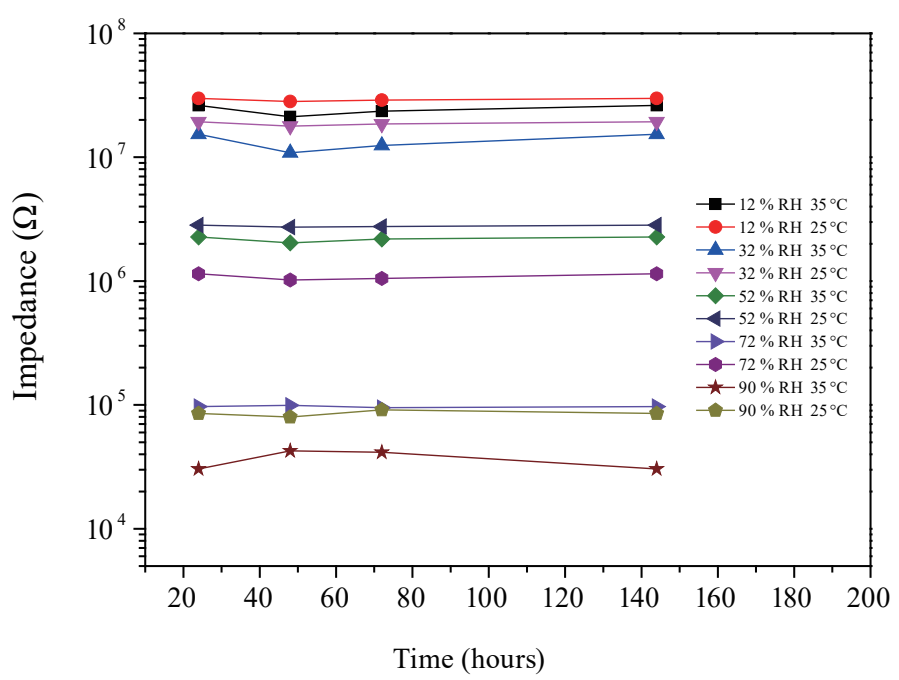

Fig. 9. (Color online) Stability of the humidity sensor based on $\mathrm{G} / \mathrm{ZrO}_{2}$ nanocomposite at temperatures of 25 and $35^{\circ} \mathrm{C}$.

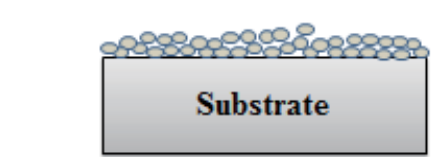

(a) $\mathrm{ZrO}_{2}$ nanoparticle structure

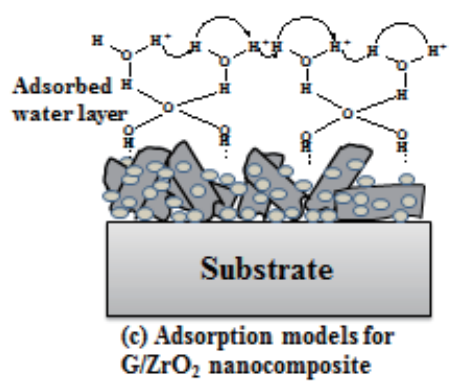

Fig. 10. (Color online) An illustration of the humidity sensing mechanism of (a) $\mathrm{ZrO}_{2}$ nanoparticle structure, (b) $\mathrm{G} / \mathrm{ZrO}_{2}$ nanocomposite structure, and (c) adsorption models for $\mathrm{G} / \mathrm{ZrO}_{2}$ nanocomposite structure. 
higher impedance at lower humidity levels. As shown in Fig. 10(c), increasing the relative humidity resulted in the formation of one or more serial water layers among the particles of the $\mathrm{G} / \mathrm{ZrO}_{2}$ nanocomposite. The serial water layers accelerate the transfer of $\mathrm{H}_{2} \mathrm{O}$ or $\mathrm{H}_{3} \mathrm{O}^{+}$. Ernsberger and Casalbore-Miceli et al. outlined an ion transfer mechanism involving the transfer of $\mathrm{H}_{2} \mathrm{O}$ or $\mathrm{H}_{3} \mathrm{O}^{+}$on serial water layers, as follows: $\mathrm{H}_{2} \mathrm{O}+\mathrm{H}_{3} \mathrm{O}^{+} \rightarrow \mathrm{H}_{3} \mathrm{O}^{+}+\mathrm{H}_{2} \mathrm{O}^{(33,34)}$ This makes the $\mathrm{G} / \mathrm{ZrO}_{2}$ nanocomposites more sensitive to humidity, which is manifest as high sensitivity, low humidity hysteresis, and quick response and recovery times, probably due to the irregular stacking of smooth graphene sheets.

\section{Conclusions}

In this study, we succeeded in the fabrication of $\mathrm{G} / \mathrm{ZrO}_{2}$ nanocomposites with a high degree of sensitivity to humidity, far exceeding the performance of $\mathrm{G} / \mathrm{ZrO}_{2}$. A sensor made with 40 wt $\%$ graphene nanocomposite provided the highest sensitivity $(S=4011)$ with low humidity hysteresis (less than 2.0\%), excellent linearity, and variations in impedance exceeding four orders in magnitude over an $\mathrm{RH}$ range of $12-90 \%$ at room temperature. The $40 \mathrm{wt} \% \mathrm{G} / \mathrm{ZrO} 2$ nanocomposite demonstrated a quick response time of $5 \mathrm{~s}$ and a recovery time and $20 \mathrm{~s}$.

\section{Acknowledgments}

The authors thank the Ministry of Science and Technology (grant no. MOST 103-2113-M562-001-) of Taiwan for support and gratefully acknowledge Department of Applied Chemistry in Providence University for their beneficial help in fabricating humidity sensors.

\section{References}

1 E. Traversa: Sens. Actuators, B 23 (1995) 135.

2 T. A. Blank, L. P. Eksperiandova, and K. N. Belikov: Sens. Actuators, B 228 (2016) 416.

3 K. P. Biju and M. K. Jain: Sens. Actuators, B 128 (2008) 407.

4 L. Gu, K. Zheng, Y. Zhou, J. Li, X. Mo, G. R. Patzke, and G. Chen: Sens. Actuators, B 159 (2011) 1.

5 V. K. Tomer and S. Duhan: Sens. Actuators, B 223 (2016) 750.

6 E. Şentürk, S. Duman, S. Bağcı, H. S. Soykan, and Z. Aslanoğlu: Sens. Actuators, A 240 (2016) 80.

7 J. Wang, M. Y. Su, J. Q. Qi, and L. Q. Chang: Sens. Actuators, B 139 (2009) 418.

8 L. Almar, A. Tarancón, T. Andreu, M. Torrell, Y. Hu, G. Dezanneau, and A. Morata: Sens. Actuators, B 216 (2015) 41.

9 M. J. Zouaoui, B. Nait-Ali, N. Glandut, and D. S. Smith: J. Eur. Ceram. Soc. 36 (2016) 163

10 W. C. Wang, Y. T. Tian, K. Li, E. Y. Lu, D. S. Gong, and X. J. Li: Appl. Surf. Sci. 273 (2013) 372.

11 P. J. Thomas and J. O. Hellevang: Sens. Actuators, B 247 (2017) 284.

12 A. Sun, L. Huang, and Y. Li: Sens. Actuators, B 139 (2009) 543.

13 Y. Yao and Y. Xue: Sens. Actuators, B 211 (2015) 52.

14 A. S. Garde: J. Alloys Compd. 617 (2014) 367.

15 H. C. Madhusudhana, S. N. Shobhadevi, B. M. Nagabhushana, B. V. Chaluvaraju, M. V. Murugendrappa, R. Hari Krishna, H. Nagabhushana, and N. R. Radeep: J. Asian Ceram. Soc. 4 (2016) 309.

16 M. K. Jain, M. C. Bhatnagar, and G. L. Sharma: Sens. Actuators, B 55 (1999) 180.

17 M. Su and J. Wang: Sens. Lett. 9 (2011) 670.

18 Z. Wang, Y. Lu, S. Yuan, L. Shi, Y. Zhao, M. Zhang, and W. Deng: J. Colloid Interf. Sci. 396 (2013) 9.

19 W. D. Lin, C. T. Liao, T. C. Chang, S. H. Chen, and R. J. Wu: Sens. Actuators, B 209 (2015) 555.

20 S. Rani, M. Aggarwal, M. Kumar, S. Sharma, and D. Kumar: Water Sci. 30 (2016) 55. 
21 L. Renuka, K. S. Anantharaju, S. C. Sharma, H. Nagabhushana, Y. S. Vidya, H. P. Nagaswarupa, and S. C. Prashantha: J. Alloys Compd. 695 (2017) 382.

22 J. T. Illakkiya, P. U. Rajalakshmi, and R. Oommen: Surf. Coat. Technol. 307 (2016) 65.

23 S. Zinatloo-Ajabshir, M. Salavati-Niasari: J. Mol-Liq. 216 (2016) 545.

24 R. K. Singha, A. Shukla, A. Yadav, S. Adak, Z. Iqbal, N. Siddiqui, and R. Bal: Appl. Energy 178 (2016) 110.

25 W. D. Lin, D. S. Lai, M. H. Chen, R. J. Wu, and F. C. Chen: Mater. Res. Bull. 48 (2013) 3822.

26 M. Su, J. Wang, H. Du, P. Yao, Y. Zheng, and X. Li: Sens. Actuators, B 161 (2012) 1038.

27 T. Alizadeh and M. Shokri: Sens. Actuators, B 222 (2016) 728.

28 D. Zhang, H. Chang, P. Li, R. Liu, and Q. Xue: Sens. Actuators, B 225 (2016) 233.

29 Z. Yuan, H. Tai, X. Bao, C. Liu, Z. Ye, and Y. Jiang: Mater. Lett. 174 (2016) 28.

30 D. Zhang, D. Wang, X. Zong, G. Dong, and Y. Zhang: Sens. Actuators, B 262 (2018) 531

31 Z. Zhu, Y. T. Guo, T. C. Chang, R. J. Wu, and W. D. Lin: Nanosci. Nanotechnol. Lett. 10 (2018) 46.

32 S. Y. Park, J. E. Lee, Y. H. Kim, J. J. Kim, Y. S. Shim, S. Y. Kim, M. H. Lee, and H. W. Jang: Sens. Actuators B 258 (2018) 775.

33 F. M. Ernsberger: J. Am. Ceram. Soc. 66 (1983) 747.

34 G. Casalbore-Miceli, M. J. Yang, N. Camaioni, C. M. Mari, Y. Li, H. Sun, and M. Ling: Solid State Ionics 131 (2000) 311. 